\title{
Ensaio
}

\section{Currículo e conhecimento escolar como mediadores epistemológicos de um projeto de nação e cidadania}

\section{Curriculum and school knowledge as epistemological mediators of the project of nation and citizenship}

Fernando José de Almeida é Prof. Dr. Titular no Programa de Educação: Currículo da PUC-SP.

\section{Contato: fernandoalmeida43@gmail.com}

\begin{abstract}
"E tu para que queres um barco, pode-se saber, foi o que de fato o rei perguntou... Para ir à procura da ilha desconhecida, respondeu o homem, Que ilha desconhecida, perguntou o rei disfarçando o riso, A ilha desconhecida, repetiu o homem, Disparate, já não há ilhas desconhecidas, Quem foi que te disse, rei, que já não há ilhas desconhecidas, Estão todas nos mapas, Nos mapas só estão as ilhas conhecidas, E que ilha desconhecida é essa que queres ir à procura, Se eu to pudesse dizer, então não seria desconhecida, A quem ouviste dizer que ela existe, perguntou o rei, agora mais sério, A ninguém, Nesse caso por que teimas em dizer que ela existe, Simplesmente porque é impossível que não exista uma ilha desconhecida,"....(Saramago).
\end{abstract}

O texto acima, irônico e metafísico a uma só vez, é de um pequeno livro de José Saramago intitulado 0 conto da ilha desconhecida, no qual está descrita a aventura políticoepistemológica de um simples súdito que quer pedir ao rei um barco para buscar a ilha desconhecida. 0 rei se espanta, mas é convencido da pertinência da aventura, depois de muita insistência do súdito. Será esta a metáfora que nos acompanhará neste breve ensaio. Aventureiro. Com os temores dos mares e com a certeza de que os céus acompanham os navegantes.

"Não precisamos mais conhecer", diria o rei de Saramago. Não é tarefa de cada um pensar ou produzir conhecimento. 
"Tudo já está conhecido."

A tarefa de conhecer é impossível perante tanta complexidade da realidade. Os temas se avolumam, a cada dia, pela quantidade e qualidade das pesquisas, pelas novidades, pela disponibilidade de dados em rede que, antes de chegarem aos destinos, já sofrem dezenas de alterações e questionamentos. A especialização e mesmo o "saber que nada sei" ficam novos a cada momento. 0 saber é a constatação diária de que nada posso saber.

Mas sei que existe o saber, o pensar, o conhecer e reconheço logo em seguida que todos esses saberes encontram-se em lugares específicos, numa matriz. Num mesmo lugar. Trata-se de uma nova forma de sermos induzidos ao pensamento: não preciso pensar, pois já pensam e produzem conhecimento por mim. Seja no Google, na Siri, na Wikipédia (como nas enciclopédias iniciadas e sonhadas por Diderot, lá no século XVIII), seja em outras centrais de pensamento, como a BMW, a Monsanto, a Microsoft, a Nasa.

O saber sobre a minha saúde encontra-se nos campos das tomografias ou nos remédios ortomoleculares, nos diagnósticos de imagens tridimensionais, na Internet das Coisas ou nas tecnologias pervasivas. A medicina familiar ou as recomendações do médico generalista se tornam frágeis perante os diagnósticos em redes das clínicas transnacionais. Escapam do indivíduo os cuidados com a própria saúde e as análises de seus sentidos. No entanto, a saúde é uma construção coletiva e, quando processada pelo indivíduo, pode dar significado à própria vida.

Por esse conjunto de ideologias pós-modernas, cada vez mais se transfere para um mundo especializado fora de nós, por atestado de incompetência pessoal, o domínio de analisar a nossa própria saúde. Deixa-se de compreender a saúde como uma construção coletiva e social, acompanhada e assimilada por projetos e intencionalidade individuais para, delegá-la a sistemas externos, incógnitos e indecifráveis. Mas os diagnósticos tecnológicos são nada perante a invasão das gorduras transgênicas e supersaturadas presentes em chips com sabor artificial de bacon ou com aroma de "ervas do jardim". Ou seja, o conhecimento oficial não é tão confiável assim. Sempre haverá ilhas desconhecidas.

Precisamos de barco. 


\section{0 poder do conhecimento social}

Nosso início de século XXI coloca a todos, discreta mas insistentemente e de formas variadas, os limites do conhecimento humano, ora em forma de acabar com os dogmas advindos de entidades superiores e do passado, ora como denúncia da própria limitação do aparelho humano de pensar e conhecer. Os erros são mais frequentes que os acertos nas ciências, as notícias falsas se sobrepõem à realidade. As ideologias agregam bilhões de pessoas levando-as à violência, à discriminação, quando não à guerra e à indiferença ao que se passa no quintal do vizinho ou ao futuro próximo.

Numa rápida síntese, o poder e a verdade se digladiam e as maiores vitórias estão contabilizadas para o poder vigente. "Os intelectualmente mais poderosos - fossem sacerdotes cristãos, mandarins, confucianos ou ideólogos comunistas - puseram a união acima da verdade. Por isso eram tão poderosos" (HARARI, 2018, p. 300).

Os métodos de verdadeira lavagem cerebral em massa estão em moda e têm tido eficácia notável em seu empenho. As eleições de presidentes norte-americanos, da África ou da América Latina têm evidenciado como as mídias e a baixa memória histórica das massas são capazes de alterar o cenário político e marchar na contramão da evolução da democracia ou dos direitos universais. A grande mídia não necessariamente retrata a verdade.

Desde os primórdios da formação e hegemonia do Homo sapiens sobre os demais hominídeos, o senso da busca de solução em grupos e as lendas, mitos ou grandes ideias são mais marcantes do que o pensamento individual. 0 homem pensa pouco sozinho. Mas em nada pode-se tirar do indivíduo sua parte.

0 ser humano se reconhece socialmente. Apostar na aprendizagem individual como forma de sobreviver e se reproduzir teria sido uma aposta aniquiladora. Sobrevivemos aos mais de 100 mil anos de nossa formação por conta de variáveis hegemônicas, como a capacidade de formar ideias mobilizadoras e a aprendizagem coletiva.

Ou seja, sempre agimos assim: a grande mídia (mesmo que fosse de pequenos grupos de 150 pessoas com uma liderança idealista, alimentada por gritos de ordem com bandeiras, causas, deuses ou medo) conduzia muitos a resultados exitosos. 
Os grandes mitos que faziam a união em torno da superação de problemas eram ideias-força. Eram poder. Nem cabe aqui falar das religiões, das artes, das ciências ou das leis (como o código de Hamurabi), mas da força geral das ideias, jogos, imagens e fantasias - ou seja, da cultura. A cultura é pensamento, mas é a partir de uma "imageria", ou fantasmagoria, ou ludicidade, que nascem de regiões da inconsciência individual ou coletiva extremamente fortes e enraizadas.

Sem criar ficção o humano não evolui.

Mas aí vem o problema. A ficção não é a verdade, nem subsiste a uma análise rigorosa da razão lógica. Então o que sobra da verdade? Consolar-se com seu lugar próprio na vida humana sem deixar de se posicionar constantemente sobre a realidade e as realidades.

0 nosso tema é conhecimento. 0 que fica dele para a escola nesse processo civilizatório e humanizador?

\section{É impossível conhecer tudo, então não precisa conhecer nada!}

Somos bombardeados, educadores, alunos, as comunidades escolares e sociais, com vertiginosa e avassaladora massa de propaganda e de desinformações. Todos somos. Não há lugar para se esconder em biblioteca alguma ou em teorias blindadas de interpretação do mundo que nos salvaguardem de erros, dúvidas, incertezas e equívocos. Ficamos impotentes e inseguros e desacreditamos em discernimentos universais ou mesmo pessoais na busca da certeza. Se o conhecimento individual não conta e não vale como interpretação e como forma de participação no mundo, que papel tem a educação, que papel tem a escola?

A tendência é imaginarmos que a escola nos abriga em um lugar protegido de dúvidas, de buscas, de incertezas, de esforços, onde o pensamento e o conhecimento venham prontos em forma de produto consumível e mercadoria cultural. Se tudo está descoberto, por que minha angústia de buscar, às vezes doloridamente, a verdade? "Já não há ilhas desconhecidas! Estão todas nos mapas", como disse o rei, em tom de descaso.

A educação formal é um caminho para manter o espaço do indivíduo, dos grupos e da sociedade; para fazer, construir, retratar, criticar e conhecer pensamentos que nos constituíram e continuam a nos constituir. 


\section{A busca continua em um mar de liquidez}

Zygmunt Bauman (2008, 2009, 2011 e 2016) vai chamar de mundo líquido as formas de amor, de economia, de amizades, de conhecimento, de modelos políticos que nos amparam e condicionam nossa vida. É dentro desse cenário, também trazido por inúmeros intérpretes da pós-modernidade (LIPOVETSKY, 2012; SERRES, 2002; DOWBOR, 2016), que o conhecimento próprio da escola tem que continuamente buscar, criar e reencontrar seu significado. Mas num mundo marcado pela ideia de que o conhecimento todo já está pronto e disponível, como fica a busca da escola?

Não é a memória sua busca. Nem a sequência de conteúdos abstratos ou mofados. Não será a erudição pedante da linguagem acadêmica ou das lógicas formais. 0 que é o conhecimento escolar, afinal? É essa a pergunta que aqui busca-se responder. Não de forma definitiva, mas no intuito de entender os limites, as potencialidades e a tarefa histórica do conhecimento escolar.

\section{As tecnologias da comunicação acirram contradições do conhecimento}

Os enormes avanços da computação, que calcula, ordena e contabiliza dados quase infinitamente, junto com a microbiologia e os estudos da genética, trazem para a competência das máquinas ações antes realizáveis pelo cérebro humano.

As atividades inteligentes, mas de caráter repetitivo, se transferem do trabalho humano para uma dimensão maquínica.

0 trabalho, algo que até hoje (na civilização judaico-cristã) é uma espécie de punição pela perda do paraíso, passa a ser tarefa das máquinas. No entanto, para a economia (da Revolução Industrial e na visão marxista), o trabalho é uma forma de manter a sociedade bem ocupada, produzindo e reproduzindo sua vida. Agora, ao passar para as máquinas algumas dessas atribuições, cabe ao homem não o ócio, desejado e prometido, mas o desemprego e a exclusão social. Como entender o fenômeno? No fundo, o pensamento mancomunado com um processo de exclusão e concentração de poder traz um conflito inesperado e não prometido como resultado da tecnificação da sociedade e da economia.

0 que fazer? Cabe à sociedade toda equacionar a solução desse novo desafio que, se não resolvido, pode ter proporções 
catastróficas. É urgente entender e solucionar o problema. Podese chamar esse fenômeno como uma das disrupções tecnológicas.

Por que esse fenômeno atinge a escola e o seu currículo? Porque a manipulação do ser humano pelo próprio humano se dá inicialmente pela manipulação dos outros com o hiperaperfeiçoamento dos campos simbólicos.

Mas há outras e variadas maneiras, ainda, de se desvalorizar o conhecimento, contraditoriamente, pela sua hipervalorização. Aqui serão enfatizadas apenas algumas.

Perante tantas complexidades do mundo, macro e microcósmico, dos poderes da matéria e das relações sociais e psíquicas, sobra para o homem comum a perplexidade imobilista em relação à sua capacidade de conhecer. Tudo já está conhecido.

\section{A síndrome da ilha desconhecida chega à escola}

De um lado, a escola é vista, a curto prazo, como um lugar para preparar as novas gerações não para o "mercado de trabalho", mas para o mundo que cerca o trabalho. mesmo sabendo - e insistindo - que a escola não cria postos de trabalho no mercado, pois este é regido por outras variáveis que não a competência do indivíduo. As competências bem formadas ajudam, mas não determinam a criação de uma vagá de trabalho no mercado da moda, nem da psicologia, nem da fonoaudiologia, nem da arquitetura, ou da engenharia naval ou da agricultura. A criação de postos de trabalho se dá na esfera dos investimentos econômicos, das taxas de moedas fortes, dos mercados internacionais, de bolsas e "commodities", assim como nas catástrofes ou em mercados emergentes, como a mecatrônica ou engenharia genética.

A insistente chamada a que as profissões do futuro nada terão a ver com as atuais tende a desmobilizar o trabalho da escola, as políticas públicas de formação e traz insegurança aos pais: o que ensinamos para o futuro? Qual o currículo comprometido com a inserção do jovem na sociedade? Em que as novas gerações irão trabalhar? Em que escola coloco meu filho?

É comum ouvir - e isso deverá aumentar muito nos próximos anos - que as profissões atuais desaparecerão e que as novas serão do tipo gestão de desenvolvimento de negócios da Inteligêencia Artificial, direção de portfólio genômico, coaching de bem-estar financeiro, técnico de saúde assistida por IA, curadoria 
de memórias pessoais, analista de cibercidades ou construtor de jornadas de realidade aumentada, entre outras.

Diante da indefinição do que significa a frase "tudo vai mudar nas profissões do futuro", pode-se cair num imobilismo cognitivo destruidor das intencionalidades próprias e necessárias para o futuro. 0 futuro que é encaminhador dos programas do presente.

Por outro lado, afirmam profeticamente alguns intelectuais desescolarizantes que a escola não tem competência de formar para o conhecimento necessário ao século XXI, este século de tantas incertezas. Frise-se que a única certeza dessa afirmação é que a escola é incapaz. Como, e por que, tanta certeza!?

Dizem: seus métodos não são gamificados, seus professores são incompetentes e medrosos, pois não se atualizam tecnologicamente. Insistem: o currículo é um mero desfile de carcomidos conteúdos sem sentido. Reforçam: as aulas são culpadas pelo desinteresse radical dos alunos que vivem num mundo cercado de facilidades e de espetáculos.

Na esteira dessas denúncias genéricas, elogia-se a educação da Finlândia, da Estônia ou da Coreia do Sul, desconsiderando o papel que a escola e sua organização curricular desempenharam na história de cada um desses países. Responder com fundamentos a tais críticas, para que se desmontem argumentações simplificadas e frequentemente distorcidas, deve ser tarefa de outros artigos e pesquisas.

Essa série de argumentos em favor da "desescolarização" culmina na busca por transferir para a família a incumbência de suprir a escola, seu currículo e sua função social e constitucional "visando o pleno desenvolvimento da pessoa, seu preparo para o exercício da cidadania e sua qualificação para o trabalho" (Art. 205 da Constituição).

Tais afirmações em favor da "desescolarização" desconsideram o significado do conhecimento escolar, que é diferente do conhecimento afetivo, cultural, testemunhal feito pela família. Importantíssimos. À escola cabe, além da socialização e da formação de valores antropológicos, trazer para os jovens, crianças e adultos as capacidades de reconhecer conteúdos amplos, historicamente consolidados e criticamente debatidos, das ciências, da literatura, das matemáticas, das línguas, da geografia, da cultura humana e da história e da compreensão do próprio corpo. 
A escola (ou o collegium, como diziam os latinos) tem uma função social de construção de um conhecimento que se desenvolve no indivíduo e se amplia para o grupo, no sentido de permitir-Ihes, como direito humano, a experiência do saber que tantas gerações produziram antes deles.

Mas a escola é também o lugar da interpretação e da utopia de recriar o mundo. Aqui trazer Paulo Freire é uma obrigação.

No colégio, na escola aprende-se a ler. Mas o que é ler?

\begin{abstract}
"Ler, segundo Freire, não é caminhar sobre as letras, mas interpretar o mundo e poder lançar sobre ele sua palavra, interferir no mundo pela ação. Ler é tomar consciência. A leitura é antes de tudo uma interpretação do mundo em que se vive. Mas não é só ler. É também representá-lo pela linguagem escrita. Falar sobre ele, interpretá-lo, reescrevê-lo. Ler e escrever neste sentido é também libertar-se. Leitura e escrita como prática da liberdade" (ALMEIDA, 2009, p. 26).
\end{abstract}

A escola é o lugar de aprender a ler. Não o b-a, bá, mas a interpretação, o sentido, a oralização da escrita, a conversa com o grupo, a troca de mundos vividos pelos alunos e pela realidade local e geral que cercam as crianças, os jovens e os adultos inseridos nela. Isso é um processo orgânico e lento de construção. Há paradas, interrogações, cansaços, retomadas, empenhos, disciplinas, atenção... diversos elementos educativos e assimilativos que o ritmo da escola (e só o da escola) tem a competência e o planejamento institucional para formar.

Paulo Freire aprofunda o sentido da educação, evidenciando nela seu caráter crítico. Almeida (2009) traz sobre o tema:

\footnotetext{
"O processo de construção da Pedagogia Crítica não é fácil nem é rápido. Ele supõe um diálogo verdadeiro (muitas vezes travestido de conversa ou de promessa eleitoral etc.) e a partir dele, a percepção das situaçõeslimite em que se encontram os educandos. Supõe também, a partir daí, o levantamento de palavras ou temas geradores e requer a decodificação dessas temáticas, para daí retirar-se as contribuições da cultura acumulada em forma de conteúdos históricos, científicos literários, das múltiplas linguagens e das tecnologias; tudo marcado pela qualidade social da educação que só se realiza num ensino de qualidade para todos" (ALMEIDA, p. 44).
}

Os meios de comunicação fornecem algumas informações importantes, mas desconectadas e fragmentadas; fora de contexto. Os ambientes virtuais oferecem grande massa de dados, 
mas pouca estrutura organizativa, uma vez que a leitura que oferecem é uma leitura baseada em links e hipertextos - ricos, sem dúvida, mas desprovidos de fins educativos formais. Santaella (2004) distingue adequadamente os tipos de leitores formados em leituras imersivas próprias do mundo digital.

\section{Novo modo de ler: mais amplo papel da escola}

Perderão as crianças ou jovens nascidos no ambiente do ciberespaço a capacidade de leitura, ou mesmo a capacidade de aprender de forma sistemática? Claro que não. Mas para isso se exige uma nova modalidade de trabalhar as funções do conhecimento escolar. É a partir da tal ampliação do trabalho sobre o conhecimento escolar que vamos nos debruçar aqui.

As provocações já prenunciadas pela TV dos anos 1960 em diante se concretizam e consolidam exponencialmente com as avalanches das redes cibernéticas? Concentração perto do zero, leituras fragmentadas em brevíssimos textos, ilustrações belíssimas e em profusão substituindo a imaginação, vivência de mundos virtuais que tocam nas bordas da realidade pelo seu dinamismo 3-D ou de avatares, onde pouco importa a distinção entre fantasia e realidade - tudo isso fará de nossos futuros leitores outros seres zumbis do ato de ler?

A perspectiva positiva sobre tais questões da formação do leitor está na busca do possível e do melhor dos mundos entre a rejeição do óbvio e a aceitação ingênua de que deixar assim é o remédio. 0 que seria isso?

Santaella $(2004,2018)$ traz uma nova perspectiva sobre a leitura, afirmando que há vários modos de ler e outros novos estão sendo construídos. Ler linguagens híbridas, mistas de imagens e textos e em ordem não sequencial, que têm uma arquitetura hipertextual - que não é a soma das múltiplas linguagens, mas é uma nova linguagem -, é a nova realidade da leitura. Tratase da adaptação do jovem e da criança a um novo mundo da perambulação e do incremento da criação de mapas mentais personalizados e irreplicáveis. Trata-se de criar, no interior dos currículos escolares e de suas metodologias, o espaço de valorização e reconhecimento dessas novas leituras. Estilos cognitivos ou opções de orientação que superem o indiferentismo ou a rejeição a priori de novas modalidades de leitura que estão sendo disponibilizadas pelas novas formas de comunicação e linguagens. Santaella vai revelar estilos de leituras (e, 
consequentemente, estilos de leitores) que ajudam a compreender a raiz de novo olhar sobre as práticas leitoras na escola.

A categoria de classificação criada por ela se dá pelos estilos de "navegação" do leitor. Trata-se, segundo Santaella (2004), de um internauta que navega, nos ares e nas virtualidades. Os textos (tecidos) são espalhados na rede e cabe ao leitor tornar a tecê-los com suas intenções, com seu equipamento interpretativo, mas também com direito a propostas de intervenção.

O leitor, novo, pode ser um errante - como quando se zapeia a TV em busca descomprometida de algo inesperado, cativante, espetacular. Não busca nada em especial, não busca o que já sabe, não precisa da memória. É um leitor errático. Há um prazer nisso. Como no primeiro dia de férias em uma cidade desconhecida, que saímos sem rumo, olhando as diferenças, as características, o passar o tempo sem pressão de resultados ou cobrança de prazos. É o prazer de flanar. Pairar sobre. Essa é uma forma de leitura contemporânea e forte. É como olhar um problema de matemática e brincar com ele procurando soluções que não se reduzam a aplicação de fórmulas ou que não sejam lição de casa. Pode ser muito prazeroso.

Mas há o leitor detetive. Que vai buscar. Ele tem outro perfil: parte do princípio de que ali naquele texto (ou contexto) há informações prováveis. Ele pensa indutivamente. Supõe a capacidade de auto-organização, de farejar indícios e de busca aleatória mas operativa. Ele trabalha na busca. "Suas estratégias de busca são acionadas mediante avanços, erros e autocorreções" (idem, p. 179).

0 leitor mais elaborado é o leitor previdente. Ele tem estilos de navegação leitora que carregam seu próprio modo de pensamento e estágio de evolução dos estudos e maturidade.

\section{Afirma Santaella:}

\footnotetext{
"Por ter internalizado os esquemas gerais subjacentes ao esquema de navegação adquiriu a habilidade de ligar os procedimentos particulares aos esquemas gerais internalizados. Sua navegação se dá em percursos ordenados, norteados por uma memória de longo prazo que o livra dos riscos inesperados" (idem, ibidem).
}

Em geral, as crianças que podem desenvolver tais habilidades precisam ser formadas para o exercício gradual da previdência leitora. 0 ambiente em si, da navegação em ambientes virtuais e de grandes redes, não favorece tais tipos de leitura. Elas são 
movidas e estimulam a navegação volátil e errante, sempre mais acelerada. É o número de toques que marca o bom leitor, pois cada toque é uma informação que o usuário oferece à rede com dados de seus desejos, valores, vontades e posições, das físicas às mentais.

À escola, com seus mecanismos de formação continuada e de construção diária de sua função na sociedade, cabe abrir-se para a aprendizagem desses novos modos de ler, que supõem o tanto que já andamos no que é leitura para irmos adiante, propondo e educando para como se lê este mundo com essas novas linguagens e mídias. Tarefa nem iniciada, mas que já é exigida às comunidades escolares.

A mídia não fará isso. Nesse contexto não nascerá espontaneamente nem emergirá daí o chamado nativo digital. Ele, largado às próprias forças, será um Mog'li brincando entre os animais da floresta ou no Éden perdido.

A leitura como um amplo papel da escola representa apenas uma fresta das questões que se nos colocam. As modalidades outras do saber escolar devem ser esmiuçadas uma a uma na busca de sua equação político-pedagógica.

As relações entre os estudantes, os papéis dos educadores, o pensamento científico, a produção social do conhecimento escolar, a avaliação/acompanhamento dos processos de aprendizagem, a sintonia com as características e dilemas afetivos da juventude, as definições de conteúdos de aprendizagem, o sentido da pesquisas escolares, os trabalhos por projetos, as grandes questões do mundo, como os ODS/Unesco ${ }^{1}$, a interdisciplinaridade, a pósverdade, entre outros, são elementos que merecem um repensar total da escola a partir desses novos desafios.

Não estamos, portanto, num momento de desescolarização, mas de repensar a função da escola nessa nova ecologia humana de um mundo transnacionalizado e de economia do conhecimento.

\section{Tudo muda: isso é uma afirmação que não muda?}

É verdade que estamos num mundo complexo, hipercomplexo, e em contínua alteração.

Quase tudo é inovado ou inovador. 0 que não mudou vai mudar. Ainda não.
1. Objetivos do Desenvolvimento Sustentável (ODS) da Unesco são um programa de cuidado com a nossa Casa Comum, a Terra, e todas as relações humanas, econômicas e sociais que buscam reverter a lógica destruidora do consumo sem fim e das relações econômicas humanas desiguais e injustas. São 17 suas metas a serem alcançadas até 2030. 
A mudança e a inovação são consideradas a priori como fatos inevitáveis e situações boas. Não é certo.

Sobra para a escola como tarefa desafiadora a função de pensar o que "não muda nas mudanças" da aprendizagem, do conhecimento e dos valores humanos.

Deles todos, o primeiro item a ser pensado são os valores.

0 que são os valores da aprendizagem, aqueles que dão força, panorama e significado de aprender, sempre e diferentemente, de acordo com as mudanças?

Aprender valores. 0 que vale. 0 que não vale. 0 que é bom e traz felicidade. Que é o bom convívio. E bem-estar. E alegria e prazer duradouro. 0 que é o bem. 0 que é a paz. 0 que é o conhecer e o que é a sabedoria. 0 que é o bem comum. Democracia, como se constrói. $O$ que é o novo. $\mathrm{E}$ o antigo. $\mathrm{O}$ que é a lembrança. $\mathrm{E}$ a recordação e a memória. 0 que é belo e digno. E justiça. E verdade. $\mathrm{O}$ que é o Outro, o diferente, o bárbaro. (Para os gregos do século $\mathrm{V}$ a.c. bárbaros eram todos os que não falavam sua língua.)

As aprendizagens de todos esses valores são as tarefas a serem realizadas pelo ambiente escolar. Mas essa tarefa não pode ser confundida ou reduzida a cursos de Filosofia.

Como o currículo escolar absorve tais temáticas, sem perder sua característica disciplinar em áreas de conhecimento, que é sua marca essencial? Onde se encontram na Geografia, na Literatura, nas línguas e suas culturas, na Educação Física, nas Ciências, nas Artes os valores acima trazidos? Os valores permeiam os conteúdos que tratamos nas atividades da escola. Os conteúdos são o rico repositório da evolução da vida dos valores na história nas ciências na literatura, nas artes, em nosso corpo. Daí, a relevância maior da escola na escolha de seu currículo e dos conteúdos que lhe darão forma.

A busca de valores e da percepção do que é bom, justo, feliz, verdadeiro ou digno nasce de perguntas germinais, aparentemente ingênuas.

\section{Quem sou eu?}

Evidencia-se aqui a absoluta e contínua tarefa humana de perguntar: conheço-me a mim mesmo? Quanto conheço? Trata-se da antiga e atual questão socrática. 
0 currículo é o repositório vivo de tudo isso. E mais.

Antes de sair buscando caminhos, a ideia da educação sistemática é saber para onde vou e porquê. Saber o que se vai fazer e ter clareza de por que ser escolhida aquela vida é anterior ao saber fazer.

Pode-se dizer, um pouco pretensiosamente, que "quem sabe faz e quem sabe por que faz, ensina". Essa será a tarefa da escola e do ensino escolar de qualidade social e humana. É a função do educador e do professor, inserida nos currículos, com clareza e consciência política.

As problemáticas acima trazidas são densas e vivas. Supõem um traçado intencional de sistematização e organicidade do tratamento dos temas. 0 currículo é seu lugar político.

\section{0 que é currículo?}

A partir de uma nova modalidade de visão - imersa em uma realidade hipercomplexa e em contínua alteração - o conceito de currículo, concebido de forma participativa e consistente, é entendido como o conjunto de ambientes e situações de aprendizagem sistematizadas, históricas e contemporâneas, que oferecem condições para as gerações se integrarem aos valores, conhecimentos e práticas sociais, compreendendo-as, criticandoas e propondo novas formas de organização da sociedade. 0 currículo escolar organiza tais estudos e vivências por meio dos conteúdos formativos mais ricos, mediados pelas práticas pedagógicas e pelos convívios sociais em redes de significados coletivos da aprendizagem.

Mas tal afirmação não esgota o sentido de currículo. Ele vai além. Ele supõe também: a consideração à diversidade de públicos e temáticas; a produção de eventos que desvelem a riqueza e os problemas sociais, que abrangem alimentação, esportes, saúde, recursos móveis, cultura, afetos, ciências etc.; o diálogo contínuo de ideias divergentes sobre minorias e diversidades de forma propositiva e respeitosa; o tratamento da memória do passado e do contemporâneo se articulando de modo harmonioso com os compromissos individuais para com o futuro; o papel das TIC na sociedade - e não a advocacia de uso de inteligências sábias do cérebro eletrônico; economia criativa; artes como belas-artes, mas também a cultura como raiz da identidade de um povo; formação do gestor, do produtor, mas também da plateia no campo das artes 
e da cultura; desenvolvimento de novas formas de leitura e de leitores do ciberespaço e dos espaços insalubres da realidade.

Desses elementos que compõem um currículo destacam-se duas conclusões:

1. Há uma visão de ser humano que está se formando e que se quer formar, sempre renovada e misteriosa.

2. Há um conceito de nação com organizadora no território e nas mentes de valores das línguas, da educação, dos espaços culturais, dos valores justos da economia e do convívio e coesão sociais, da preservação da casa comum da natureza e da cultura...

Tais projetos de homem e de nação se consolidam, se analisam e se reformulam no interior do currículo pelas suas áreas próprias de conhecimento: formal, orgânico e inovador.

A sua compreensão e sua realização se concretizam na Matemática, na História, na localização no território - nas diferentes cartografias dos espaços humanos, da mente, dos grupos políticos, da psicologia, das guerras, da literatura mundial, dos museus, da memória humana, das línguas, das culturas estrangeiras, próximas e nos tempos primeiros, das culturas da saúde, dos jogos, das comunicações visuais, dos mapas mentais. 0 ser humano é animal e está numa biosfera. 0 que significa para ele essa constatação e os desmembramentos da constatação, ou seja, de que a espécie humana vive num mundo limitado ao ar, à água e à terra, mas, também, ao espaço íntimo de uma singularidade?

0 que nos faz homens e mulheres é a participação emocional e cognitiva em um espaço que não é o do condomínio nem o dos shoppings, nem o das poltronas de aviões, mas o espaço do mundo vivo e real de bilhões de seres em contaminações diárias de suas mágoas e grandezas.

Portanto, a dimensão mais rica do currículo é a vida como ela está dada.

\section{A especificidade do conhecimento escolar}

o conhecimento escolar tem sua origem em todos os conhecimentos produzidos pela sociedade, mas com nenhum deles se confunde. Nenhuma agência social faz algo que substitua a escola. Não é o conhecimento político, não é o conhecimento 
da fé, nem é o conhecimento afetivo, não é o conhecimento das operações bancárias nem da guerra. É o conhecimento epistemológico. Trata-se do pensar sobre o pensar, sobre o significado e a inteligibilidade dos fenômenos sociais, artísticos, científicos sobre a vida. A educação dentro do contexto de futuro tem a incumbência de ensinar a pensar, a interpretar o mundo, a diagnosticá-lo, a escrevê-lo em suas múltiplas linguagens, a dedicar-se às linguagens das letras, das cartografias, dos gestos, dos números, assim como às das ciências, às do corpo e das artes. Seu domínio é a epistemologia. Ou seja, o conhecimento sistematizado, que reflete sobre si e tem regras. A escola compreende que a inteligência humana é múltipla e toda ela deva ser desenvolvida harmoniosamente, mas o currículo escolar não pode abranger todas as suas dimensões pelas limitações de tempo e de seu escopo. Como a vida concreta (como sentimentos, política, cultura, ética) tange o espaço do conhecimento escolar? Por exemplo, as emoções. Elas se originam no espaço familiar e se desenvolvem em todas as outras instituições. Evoluem, vão da sua dimensão psicológica à convivial e da estética à ética. À escola não cabe formar os jovens e adultos nessa dimensão, a não ser pela compreensão do papel que elas jogam no cenário da aprendizagem geral do estudante e em sua visão de mundo. Não educo para o afeto, mas educo para aquilo que afeta o conhecimento. É fornecido ao estudante os elementos de entendimento dos fenômenos do afeto emotivo, por meio daquilo que afeta os componentes da educação. Entender o afeto significa vê-lo retratado na literatura, ou na biologia, na psicologia, nos trabalhos em grupo e suas regras, no saber ouvir, nas atividades concretas de sala de aula ou nos estudos do meio, e não dar aulas sobre o que é o afeto genericamente. Outro exemplo: as dimensões do poder (político) concentram-se na ágora, nas tratativas negociais, econômicas, passam pelas organizações políticas do Estado, dos sindicatos, das guildas, das associações de grupos, dos setores produtivos, ou das universidades corporativas. Enfim, nos partidos políticos - venham eles de Maquiavel, da democracia grega ou das agremiações estudantis. À escola cabe entendê-las, conhecê-las na história, ver-lhes as dimensões econômicas, as implicações éticas, mas não formar os estudantes para opção ou militância partidária. As preocupações da fé, transcendência, os ritos, as organizações das religações do ser humano com o divino se articulam em torno das religiões e padrões das práticas que nascem de grandes explicações do mundo da vida para além do que se vê e experimenta. De novo, a escola pode ser o lugar da compreensão do fenômeno humano sobre a transcendência, mas ela não é o lugar da doutrinação religiosa. 
Por que se trazem aqui três exemplos de temas que se aproximam do conhecimento escolar e não são suas finalidades? Porque um dos problemas que a escola enfrenta neste início de século é que todas as instituições veem na escola e em seu currículo um espaço notável de divulgar seus valores e suas intenções, de venda, de proselitismo ou de novidades falsamente modernizadoras. Centrar a "aprendizagem educacional escolar" no que é de fato seu fim é uma tarefa cada vez mais difícil e necessária. Outro grande desafio que a escola - e toda a sociedade - enfrenta é o alargamento de campos da Inteligência Artificial. Saber dos avanços e fazer uso dos conhecimentos que a Inteligência Artificial traz sobre a inteligência natural é da maior importância, e função da escola. Principalmente no que diz respeito à tangência que a IA já faz ao terreno da sobreposição à consciência. Como simulacro pode-se entendê-la, mas como substituição, impossível.

\section{Conclusão}

Acima foram apresentados alguns desafios que se fazem à escola formal - que vem tendo uma função civilizatória marcante nos últimos dois séculos. Temos que nos defrontar com eles, seja para dizer "chega de escola, ela já cumpriu seu papel!",seja para anunciar "A escola, mais do que nunca, continua sendo um espaço social de humanização, de formação de cidadania e de valores de liberdade e de conhecimento sistematizado". Para isso precisa se reconhecer.

A ilha desconhecida continua lá. Mas, agora, depois de algumas idas e vindas das reflexões apresentadas neste artigo, percebemos um guia. Na própria metáfora de Saramago (2011) podemos nos inspirar: "Que é necessário sair da ilha para ver a ilha, que não nos vemos se não saímos de nós mesmos, Se não saímos de nós próprios, queres tu dizer" (p. 62)...

E a metáfora se encerra, abrindo nova metáfora que pode, sem dúvida, abrir questões ao texto aqui produzido. Diz Saramago ao encerrar o conto: "Depois, mal o sol acabou de nascer, o homem e a mulher foram pintar na proa do barco, de um lado e de outro, em letras brancas, o nome que ainda faltava dar à caravela. Pela hora do meio-dia, com a maré, A Ilha Desconhecida, fez-se enfim ao mar, à procura de si mesma." (p.62). 


\section{REFERÊNCIAS BIBLIOGRÁFICAS}

ALMEIDA, F.J. FOLHA explica Paulo Freire. São Paulo:

Publifolha, 2009.

ALMEIDA F.J.; SILVA, M.G.M. "Currículo e conhecimento escolar como mediadores epistemológicos do projeto de nação e cidadania". Revista E-currículo. V. 16, n.3 (2018).

BAUMAN, Zygmunt. A vida para o consumo. Rio de Janeiro: Zahar, 2008

Confiança e medo na cidade. Rio de Janeiro: Zahar, 2009

Ética é possível num mundo de consumidores?

Rio de Janeiro: Zahar, 2011

e Bordoni, C. Estado de Crise. Rio de Janeiro: Zahar,

2016

DOWBOR, Ladislau. O pão nosso de cada dia. Imperatriz, MA:

Ética, 2016

LIPOVETSKY, Gilles; JUVIN, Hervé. A Globalização Ocidental.

São Paulo: Manole, 2012.

LIPOVETSKY, G. A Sociedade da Decepção. São Paulo: Manole, 2007.

SANTAELLA, L. Navegar no ciberespaço. São Paulo: Paulus, 2004.

.Comunicação ubíqua: repercussões na cultura e na educação. São Paulo: Paulus, 2013.

SARAMAGO, J. O Conto da ilha desconhecida. São Paulo: Cia. das Letras, 2011. 
SERRES, M.; PICQ, P.; VINCENT, Jean-Didier. Qu'est-ce que I'humain? Paris: Le Pommier, 2003.

Recebido: 30/10/2018

Revisto: 29/01/2019

Aceito: 10/12/2018 